\title{
Nickel Deficiency Affects Nitrogenous Forms and Urease Activity in Spring Xylem Sap of Pecan
}

\author{
Cheng Bai, Charles C. Reilly, and Bruce W. Wood ${ }^{1}$ \\ U.S. Department of Agriculture, Agricultural Research Service, South Atlantic Area, Southeast Fruit \\ and Tree Nut Research Laboratory, Byron, GA 31008
}

\begin{abstract}
AdDitional INDEX words. Carya illinoinensis, ureide catabolism, urea cycle, amides, nitrogen metabolism
Abstract. While nickel (Ni) deficiency occurs in certain agricultural crops, little is known regarding the influence of deficiency on metabolic or physiological processes. We studied the influence of $\mathrm{Ni}$ deficiency on the reduced-nitrogen (N) composition of early spring xylem sap of pecan [Carya illinoinensis (Wangenh.) C. Koch]. High-performance liquid chromatography (HPLC) analysis of sap composition found the presence of ureido-, amide-, and amino-N substances and that they are quantitatively influenced by tree $\mathrm{Ni}$ nutritional status. Ureido- $\mathrm{N}$ forms quantitatively dominated amide- $\mathrm{N}$ forms with respect to both molar concentration and the forms in which reduced $\mathrm{N}$ atoms are present; thus, pecan appears to be predominately a ureide-transporting species. The primary ureido- $\mathrm{N}$ substances in sap of Ni-sufficient trees are citrulline $\approx$ asparagine $\approx$ xanthine $>$ ureidoglycolate $>$ allantoic acid $>$ allantoin $\approx$ uric acid $\approx$ urea. Asparagine is the primary amide- $\mathrm{N}$ form, while only traces of amino-N forms (e.g., tryptamine and $\beta$-phenylethylamine) are found in xylem sap. Nickel deficiency substantially increased citrulline and allantoic acid in xylem sap while decreasing the asparagine, xanthine, and $\beta$-phenylethylamine concentrations. These Ni-linked quantitative shifts in reduced-N forms indicate that $\mathrm{Ni}$ nutrition potentially affects intermediates of both the ureide catabolic pathway and the urea cycle as well as the nitrogen/carbon (N/C) economy of the tree. Xylem sap-associated urease-specific activity was also reduced as a consequence of $\mathrm{Ni}$ deficiency. These results indicate that Ni deficiency potentially disrupts normal $\mathrm{N}$-cycling via disruption of ureide metabolism.
\end{abstract}

Nickel was suspected of possessing a metabolic role in plants when it was discovered as a constituent of plant ash in the early 20th century. Evidence for a key metabolic role was strengthened with observation of field-level growth responses to foliar Ni applications to crops as diverse as wheat (Triticum aestivum L.), potato (Solanum tuberosum L.), and broad bean (Vicia faba L.) (Dobrolyubskii and Slavvo, 1957; Roach and Barclay, 1946; Welch, 1981). The likelihood of an essential role for $\mathrm{Ni}$ became evident with the discovery that urease (EC 3.5.1.5, urea amidohydrolase), a ubiquitous enzyme in plant organs, requires Ni for activation (Dixon et al., 1975). Subsequent research by Brown et al. (1987a, 1987b) found that $\mathrm{Ni}$ met generally accepted criteria for an essential element. Nickel deficiency in crops was first reported for field situations when Wood et al. (2004b) discovered deficiency in orchard trees of pecan. Subsequent observations found that severe Ni deficiency can potentially harm plants by disrupting normal growth to cause growth disorders, termed "mouse-ear" or "little-leaf" (Ruter, 2005; Wood et al., 2004a, 2006); by affecting longevity by causing an orchard replant malady found in secondgeneration pecan orchards (Wood et al., 2004a, 2004b, 2004c); by affecting disease resistance (Reilly et al., 2005); and by disrupting primary and secondary physiological processes, such as carbon anabolism and nitrogen catabolism (Bai et al., 2006).

Nickel deficiency potentially disrupts $\mathrm{N}$ metabolism in plants. Young foliage of severely Ni-deficient pecan trees

Received for publication 8 Aug. 2006. Accepted for publication 28 Feb. 2007. Mention of a trademark, proprietary product, or vendor does not constitute a guarantee or warranty of the product by the U.S. Department of Agriculture and does not imply its approval at the exclusion of other products or vendors that may also be suitable.

${ }^{1}$ Corresponding author. E-mail: bwwood@saa.ars.usda.gov. exhibits metabolic disruption of $\mathrm{N}$ metabolism via ureide catabolism, amino acid metabolism, and ornithine-cycle intermediates; additionally, deficiency disrupts the citric acid-cycle carbon metabolism (Bai et al., 2006). Specifically, Ni deficiency disrupts ureide catabolism in young pecan foliage to cause an accumulation of xanthine, allantoic acid, ureidoglycolate, and citrulline. There are also reports of low-Niassociated disruption of urea metabolism, thus causing an accumulation of urea in foliage of soybean [Glycine max (L.) Merr.] and cowpea (Vigna unguiculata L.) (Eskew et al., 1983, 1984; Walker et al., 1985). Nickel deficiency also affects amino acid metabolism in cowpea (Walker et al., 1985); reduces urease activity; induces metabolic nitrogen deficiency; and affects amino acids, amides (glutamine and asparagine), and urea-cycle intermediates (arginine, ornithine, and citrulline) in several nonwoody species [rye (Secale cereale L.), wheat, soybean, rape (Brassica tournefortii Gouan), zucchini (Cucurbita pepo L.), and sunflower (Helianthus annuus L.) (Gerendás and Sattelmacher, 1997)]. Similar disruptions occur in barley (Hordeum bulbosum L.) where Ni deficiency disrupts metabolism of amino acids, malate, and certain inorganic anions (e.g., $\mathrm{SO}^{4}, \mathrm{Cl}^{-}, \mathrm{P}_{\mathrm{i}}$, and $\mathrm{NO}^{3-}$ ) (Brown et al., 1990). Thus, poor $\mathrm{Ni}$ nutrition potentially affects $\mathrm{N}$ metabolism in a wide variety of crop species. Because of the importance of timely $\mathrm{N}$ storage, translocation, and cycling, it stands that timely mobilization and conversion of $\mathrm{N}$ reserves during early spring, when active growth begins in aboveground organs, is critical to the survival of long-lived woody perennial crops. The influences of $\mathrm{Ni}$ deficiency on $\mathrm{N}$ metabolism described above indicate that $\mathrm{Ni}$ deficiency can potentially influence efficiency of $\mathrm{N}$ conversion of plant $\mathrm{N}$ reserves as well as that of $\mathrm{N}$ management of agricultural ecosystems. Thus, the interaction of $\mathrm{N}$ and $\mathrm{Ni}$ are potentially of importance from perspectives of pollution, cost, and plant productivity. Orchard ecosystems typically receive 
substantial annual spring $\mathrm{N}$ inputs as fertilizer amendments (i.e., $\mathrm{N}$ at $100-300 \mathrm{~kg} \cdot \mathrm{ha}^{-1}$ ); yet, little is known of how plant $\mathrm{Ni}$ status affects $\mathrm{N}$-associated metabolism and physiology.

Woody perennials store considerable organic reduced $\mathrm{N}$ in roots, and also possibly in aboveground structures, during dormancy. During early spring, this $\mathrm{N}$ pool, some of which is in soluble proteins that undergo enzymatic hydrolysis, is mobilized and translocated as reduced organic $\mathrm{N}$ moving in xylem sap to sinks in the canopy (Ourry et al., 2001). Most of this translocating $\mathrm{N}$ is in the form of amino acids, amides, or ureides (Schubert and Boland, 1990). The process is reversed in the autumn when proteins, nucleic acids, and other N-containing compounds are degraded in senescing foliage to ureides, amides, and amino acids and translocated to perennial organs for storage until the next growing season (Schubert and Boland, 1990). The primary N-form that is translocated varies depending on species, but many species native to hydrophilic habitats, possessing organic, moist, well-drained soils, transport $\mathrm{N}$ primarily as ureides (e.g., allantoin, allantoic acid, uric acid, xanthine, and citrulline). For example, woody perennial genera with certain species primarily transporting ureide-N are Acer L., Alnus Mill., Annona L., Betula L., Carpinus L., Cercis L., Chamaecyparis Spach, Cornus L., Corylus L., Diospyros L., Juglans L., Nothofagus Blume , Ostrya Scop., Platanus L., Populus L., Pterocarya Kunth, Salix L., and Vitis L. (Schubert and Boland, 1990). Additionally, legumes of tropical origin \{e.g., soybean, kidney bean (Phaseolus vulgaris L.), peanut (Arachis hypogea L.), and southernpea [Vigna unguiculata cylindrical (L.) Eselt.]\} also predominately transport $\mathrm{N}$ as ureides, whereas those of temperate origin [garden pea (Pisum sativum L.), clover (Trifolium incarnatum L.), broad bean, and lentil (Lens culinaris Medik.)] typically transport $\mathrm{N}$ as amides (Bloom, 2002). The potential for Ni deficiency to disrupt ureide catabolism in pecan (Bai et al., 2006) indicates that pecan may be a ureide transporter and hints that ureide-transporting species may be more prone to $\mathrm{Ni}$ deficiency than are amineor amide-transporting species. Thus the potential for disruption of normal $\mathrm{N}$ metabolism by poor $\mathrm{Ni}$ nutrition indicates that the translocating forms of reduced $\mathrm{N}$ in spring xylem sap of pecan may be affected by $\mathrm{Ni}$ deficiency. We hypothesize that 1 ) endogenous Ni nutritional status affects the relative composition of reduced-N forms in early spring xylem sap of pecan and that 2) pecan transports reduced organic $\mathrm{N}$ primarily as ureides.

\section{Materials and Methods}

Plant Materials. Presence of primary amide-N and ureido$\mathrm{N}$ forms in the N-rich early spring xylem sap of pecan was determined by HPLC analysis of xylem sap collected at the time of bud break. Bud break is defined here as the inner bud scale split of $>50 \%$ of primary apical buds. Spring xylem sap was collected and analyzed at the same stage of bud break from trees reflecting two distinct states of Ni nutritional status [i.e., Ni sufficient (Ni-S) vs. Ni deficient (Ni-D)].

The Ni-S and Ni-D treatment classes of plants were obtained from 3 -year-old pecan trees growing in a greenhouse in Georgia (lat. $32^{\circ} 39^{\prime} 54^{\prime \prime} \mathrm{N}$, long. $83^{\circ} 44^{\prime} 31^{\prime \prime} \mathrm{W}$ ). Trees grew in plastic pots $(20 \times 20 \times 20 \mathrm{~cm})$ filled with the uppermost $5 \mathrm{~cm}$ of a Tifton Loamy Sand soil profile collected from a southern Georgia orchard exhibiting Ni deficiency in mature trees. These potted trees exhibited morphological Ni-deficiency symptoms on a frequency of $\approx 30 \%$ (i.e., $70 \%$ appearing normal), with about $5 \%$ exhibiting severe Ni deficiency. The population $(n=$ 365 ) of seedling trees exhibiting severe morphological $\mathrm{Ni}$ symptoms in the previous and current growing season were considered in this study to be $\mathrm{Ni}$ deficient, whereas the population (i.e., 24 trees) not exhibiting Ni-deficiency symptoms during the previous or current year were designated as $\mathrm{Ni}$ sufficient. Trees were well managed regarding essential mineral nutrient elements, with the $100 \%$ orchard soil providing all necessary nutrients except for $\mathrm{Ni}$. Trees were not fertilized with any standard nutrient element other than that of $\mathrm{N}$ because of the potential for contaminating treatments with $\mathrm{Ni}$ from fertilizer sources, especially from phosphorus (P) and micronutrient sources. Even a trace addition of Ni can satisfy plant needs. Tissue analysis of mature foliage of adjacent trees corresponding to the Ni-S and Ni-D class test plants during July indicated that all macro- and micronutrients were present at sufficiency levels established for pecan by the Georgia Cooperative Extension, except for that of $\mathrm{Ni}$ in the Ni-D treatment test trees. Additionally, test plants did not exhibit visual symptoms of any macro- or micronutrient deficiency other than that of $\mathrm{Ni}$ in the Ni-D treatments. All treatment trees received an equivalent amount of supplemental $\mathrm{N}$ as ammonium nitrate the previous growing season $(10 \mathrm{~g} / \mathrm{pot})$ and again in February (10 g/pot) of the current growing season; thus, neither treatment was limited by soil N. Ni-S trees had July leaf Ni levels of $1-4 \mu \mathrm{g} \cdot \mathrm{g}^{-1}$ dry weight, which is considered to be in the "sufficient" range, based on morphological abnormalities, for $\mathrm{Ni}$ in pecan (Nyczepir et al., 2006). The Ni-D class was distinguished on the basis of classical morphological symptoms of Ni deficiency (Wood et al., 2004a) exhibited the prior growing season and verified by Ni-associated abnormalities of breaking buds at time of xylem sap collection. July Ni concentration in foliage of Ni-D trees was $0.004-0.540 \mu \mathrm{g} \cdot \mathrm{g}^{-1}$ dry weight.

XYlem SAP COllection. Xylem sap samples were collected from several Ni-D and Ni-S trees at bud break on March 24. Sap was vacuum extracted from stems severed $\approx 2 \mathrm{~cm}$ above the root collar and again just below the apical tip. The bark and phloem were removed for $1 \mathrm{~cm}$ above the basal end of the stems to exclude phloem sap contamination of the xylem sap sample. The base of severed stems was then placed in a vacuum chamber, and exuding xylem sap dripped into $2-\mathrm{mL}$ vials and was immediately frozen at $-70^{\circ} \mathrm{C}$.

Xylem sap samples from 12 representative trees of each of the two Ni treatments were randomly selected and then processed in triplicate for reduced-N and urease analysis. Equivalent volumes of xylem sap for each sample were thawed and twice centrifuged $(20,000 \mathrm{~g})$ for $30 \mathrm{~min}$. The supernatant was further purified by removing molecules $\geq 10 \mathrm{kDa}$ by twice filtering through a Centricon-10 filter (Millipore Filter Units, Millipore, Bedford, Mass.) after centrifugation (5000g) for $75 \mathrm{~min}$. The partially purified samples were then analyzed for ureides using ultraviolet (UV) spectroscopy and HPLC. For identification purposes, samples were processed on two different HPLC columns with different elute phases. The proteins were concentrated and dissolved in Buffer E (Bai et al., 1999). The resulting protein solution (molecular mass $\geq 10 \mathrm{kDa}$ ) was then analyzed for urease activity as described below.

HPLC ANALYSIS OF THE $\leq \mathbf{1 0 - k D a ~ F R A C T I O N . ~ E a c h ~ x y l e m ~}$ sap sample was analyzed in triplicate for ureides and amides using an HPLC Spectra System SCM 1000 linked with the Spectra System ultraviolet 1000 detector in association with a 
Platinum EPS C18 column $(5 \mu \mathrm{m}, 250 \times 4.6 \mathrm{~mm}$; Alltech Associates, Deerfield, Ill.). The mobile phase was acetonitrile and $0.03 \mathrm{M}$ potassium phosphate, $\mathrm{pH} 3.2$ (20:80), at 0.5 $\mathrm{mL} \cdot \mathrm{min}^{-1}$ and $30{ }^{\circ} \mathrm{C}$. Sample injection volume was $20 \mu \mathrm{L}$ of the above-described partially purified fractions. Detection was at $190 \mathrm{~nm}$. Tentative ureide identification was based on identical retention times compared with ureide and amide standards. Reference chemicals were xanthine, uric acid, allantoin, allantoic acid, glyoxylic acid, urea, $\beta$-phenylethylamine, L-asparagine, and tryptamine (Sigma, St. Louis). The standards and internal standards were used at concentrations ranging from 100 to $400 \mu \mathrm{M} \cdot \mathrm{mL}^{-1}$ [in acetonitrile, $0.03 \mathrm{M}$ potassium phosphate monobasic, $\mathrm{pH} 3.2$ (20:80)]. Ureidoglycolate was synthesized by reacting urea with glyoxylic acid. Absorbencies of reference chemicals were greatest at $190 \mathrm{~nm}$, thus the analysis was conducted at $190 \mathrm{~nm}$. In addition, to confirm the identification of ureides (e.g., allantoic acid, asparagine, citrulline, uric acid, urea, xanthine, allantoin, and ureidoglycolate), samples were also run on a ZORBAX Rx-SIL (Agilent Technologies, Palo Alto, Calif.) column (5 $\mu \mathrm{m}, 4.6$ $\mathrm{mm} \times 150 \mathrm{~mm}$ ) with a mobile phase consisting of acetonitrile and $20 \mathrm{~mm}$ potassium phosphate, $\mathrm{pH} 7.2$ (90:10). Wellseparated symmetric peaks appearing after mixing xylem sap sample with standard, and running HPLC, are considered to be the same chemical substance. Retention times, in minutes, for nitrogenous compounds were 5.50 for allantoic acid, 5.82 for asparagine, 5.89 for citrulline, 5.93 for allantoin, 6.06 for uric acid, 6.14 for urea, 6.90 for xanthine, 7.26 for ureidoglycolate, 10.89 for $\beta$-phenylethylamine, and 13.57 for tryptamine using the Platinum EPS C18 column $(5 \mu \mathrm{m}, 250 \mathrm{~mm} \times 4.6 \mathrm{~mm}$; Alltech Associates) as described above. $\beta$-Phenylethylamine is an alkaloid that is likely a consequence of enzymatic decarboxylation of phenylalanine.

ASSAY OF UREASE ACTIVITY OF THE $\geq 10$-kDa FRACTION. Urease catalyzes the hydrolysis of urea. Urease activity was determined based on the methods of Kaltwasser and Schlegel (1966), but with slight modification (Bai et al., 2006). The hydrolysis of urea was measured by coupling ammonia production to a Glu dehydrogenase reaction. All chemical reagents used for enzyme assay were dissolved in $0.1 \mathrm{M}$ potassium phosphate buffer ( $\mathrm{pH} 7.6$ ). The assay mixture was $0.37 \mathrm{~mL}$ of $0.1 \mathrm{M}$ potassium phosphate buffer $(\mathrm{pH} 7.6), 0.1 \mathrm{~mL}$ of $1.8 \mathrm{M}$ urea, $0.1 \mathrm{~mL}$ of $0.025 \mathrm{M}$ ADP, $0.2 \mathrm{~mL}$ of $0.008 \mathrm{M} \mathrm{NADH}$, $0.1 \mathrm{~mL}$ of $0.025 \mathrm{M} \alpha$-ketoglutarate; then $0.1 \mathrm{~mL}$ of 50 units $/ \mathrm{mL}$ Glu dehydrogenase and $5 \mu \mathrm{L}$ of enzyme solution were added. The change in $A_{340}$ at $25{ }^{\circ} \mathrm{C}$ was recorded at $0.5,1,3$, and $5 \mathrm{~min}$. Urease from jack bean (Canavalia ensiformis L.) (29.5 units/ $\mathrm{mg}$; Sigma) was used as a reference. A unit is defined as the amount of urease causing oxidation of $1 \mu \mathrm{M}$ of $\mathrm{NADH} \cdot \mathrm{min}^{-1}$ at $25^{\circ} \mathrm{C}, \mathrm{pH} 7.6$, in a coupled reaction using Glu dehydrogenase. Protein concentration was determined via the Bio-Rad protein assay with bovine serum albumin as standard.

Statistical analysis. Twelve specimens from each of the two Ni status classes (i.e., 24 trees) were randomly chosen from among the two Ni deficiency class populations. Because only a small volume of sap could be collected per tree $(\leq 0.50 \mathrm{~mL})$, sap extracted from four trees was bulked to represent an experimental unit for each of the two Ni treatment classes for each of three replicates. Individual samples were then analyzed in triplicate. The statistical design was therefore a completely randomized block, composed of three replicates, with each replicate being comprised of xylem sap from four trees.
Statistical analysis was via analysis of variance at the $\alpha \leq$ 0.05 level.

\section{Results}

HPLC analysis found early spring xylem sap to be composed of at least seven ureido-N substances (allantoic acid, allantoin, citrulline, uric acid, urea, xanthine, and ureidoglycolate), one amide-N (asparagine), and two amino-N substances (tryptamine and $\beta$-phenylethylamine) (Figs. 1-3). When viewed collectively within the context of $\mathrm{Ni}-\mathrm{S}$ trees, the relative abundance of these reduced-N forms in xylem sap is citrulline $\approx$ asparagine $\approx$ xanthine $>$ ureidoglycolate $>$ allantoic acid $>\beta$ phenylethylamine. Allantoin, urea, uric acid, and tryptamine are present at trace levels. Ni status did not detectably influence, in a qualitative manner, the forms of reduced-N occurring in early spring xylem sap.

Xylem sap also contained urease and various unidentified proteins. Xylem sap urease activity was affected by tree $\mathrm{Ni}$ status, with specific activity being lower in xylem sap from Ni$\mathrm{D}$ than from Ni-S trees (Table 1). Substances of the ureide catabolic pathway were also affected in that $\mathrm{Ni}$ deficiency substantially reduced the concentration of xanthine but increased allantoic acid in spring sap of Ni-D trees (Fig. 1); concentrations of ureidoglycolate, allantoin, and uric acid were not detectably influenced. Ni deficiency also influenced intermediates of the urea cycle in that the concentrations of asparagine declined and citrulline increased as a consequence of Ni deficiency (Fig. 2). The concentration of $\beta$-phenylethylamine in sap also declined as a consequence of $\mathrm{Ni}$ deficiency (Fig. 3).

The ureido-, amide-, and amino- $\mathrm{N}$ components of xylem sap contain different numbers of $\mathrm{N}$-atoms per molecule and thus possess different $\mathrm{N} / \mathrm{C}$ ratios (Table 2). Examination of xylem sap constituents, within the context of the molecular forms in which most reduced $\mathrm{N}$-atoms are being translocated, found that ureido-N dominates (Table 2; Figs. 4-6). Ni nutritional status had little or no effect on the relative percentage of total organic reduced-N $\mathrm{N}$-atoms present in xylem sap, with $\mathrm{N}$-atoms being $\approx 85 \%$ ureide- $\mathrm{N}, \approx 14 \%$ amide- $\mathrm{N}$, and $\approx 1 \%$ amino-N. However, under conditions of $\mathrm{Ni}$ deficiency, organic reduced $\mathrm{N}$ atoms were substantially influenced, leading to a reduction in xanthine (from $\approx 18 \%$ to $\approx 5 \%$; Fig. 3 ) and an increase in citrulline ( $\approx 26 \%$ to $\approx 45 \%$; Fig. 4 ). Thus Ni deficiency caused a major quantitative shift in sap composition, with citrulline replacing xanthine as the primary form for $\mathrm{N}$-atoms present as either ureido-, amide-, or amino-N forms in early spring xylem sap.

\section{Discussion}

The key role of $\mathrm{Ni}$ in the activation of known plant ureases (Dixon et al., 1975; Sirko and Brodzik, 2000), its presence in pecan xylem sap, and the observed reduction in activity in Nideficient trees indicate that xylem sap urease (and pecan leaf urease) is also a Ni-metalloenzyme. The occurrence of active urease in xylem sap indicates that urea catabolism occurs during transport, thus releasing ammonium-N into the xylem stream as $\mathrm{N}$ is transported to sinks. This means that $\mathrm{Ni}$ deficiency suppresses urease activity during a critical growth stage when the sink demand for organic $\mathrm{N}$ is high. Such a 

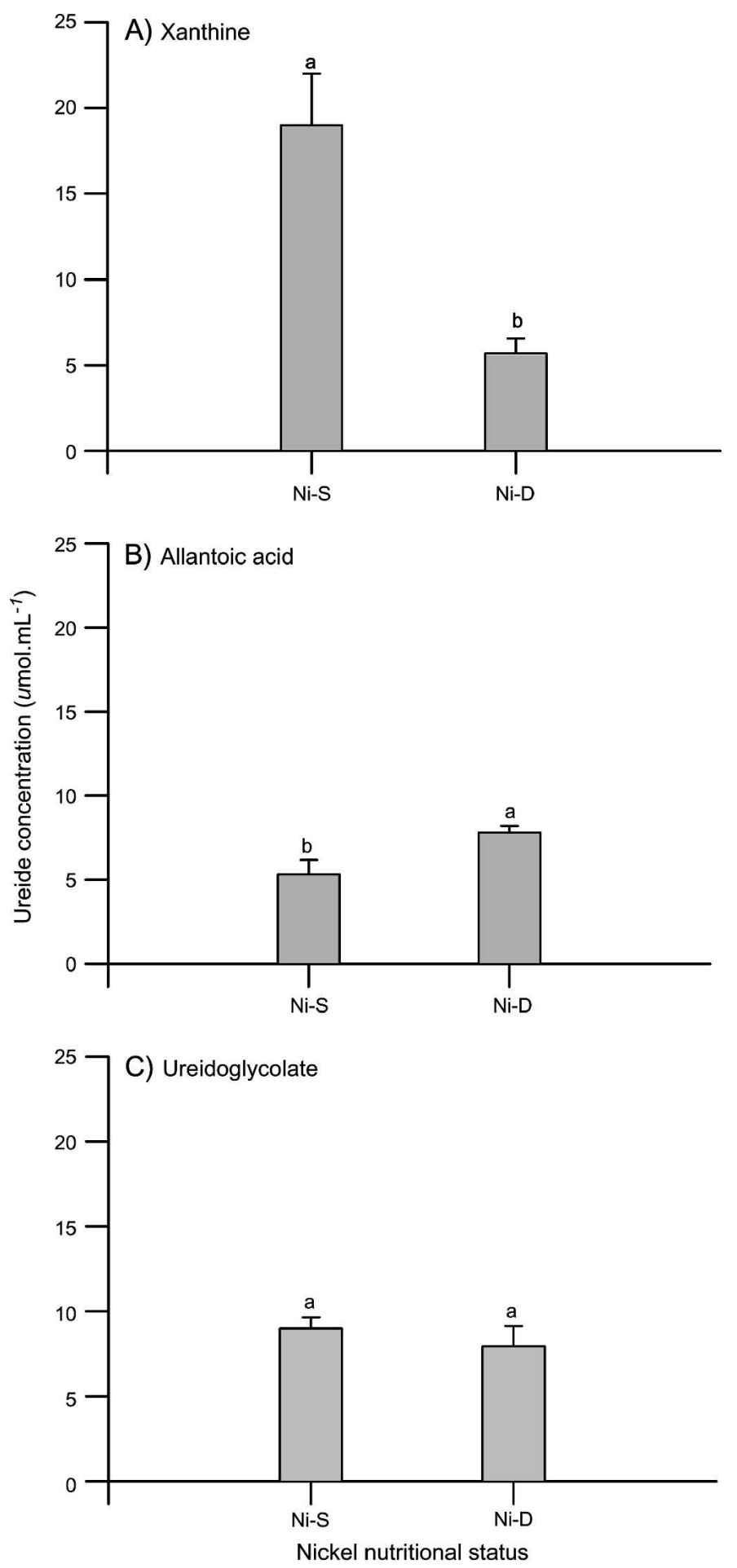

Fig. 1. Influence of pecan tree nickel nutritional status [Ni-deficient (Ni-D) and $\mathrm{Ni}$-sufficient (Ni-S)] on concentration of the ureido-N present in spring xylem sap at bud break. Xanthine (A), allantoic acid (B), and ureidoglycolate (C) are the most abundant ureides. Allantoin, uric acid, urea, and tryptamine are also present, but at trace levels $\left(\leq 0.50 \mu \mathrm{mol} \cdot \mathrm{mL}^{-1}\right)$. Different letters above the bar for each ureide designates statistical difference by ANOVA at $\alpha=0.05$.

disruption potentially affects a host of growth-associated processes impacting plant productivity (e.g., biosynthesis of proteins, enzymes, and nucleic acids; photoassimilation and leaf area; flowering and fruit-drop; and shoot and canopy

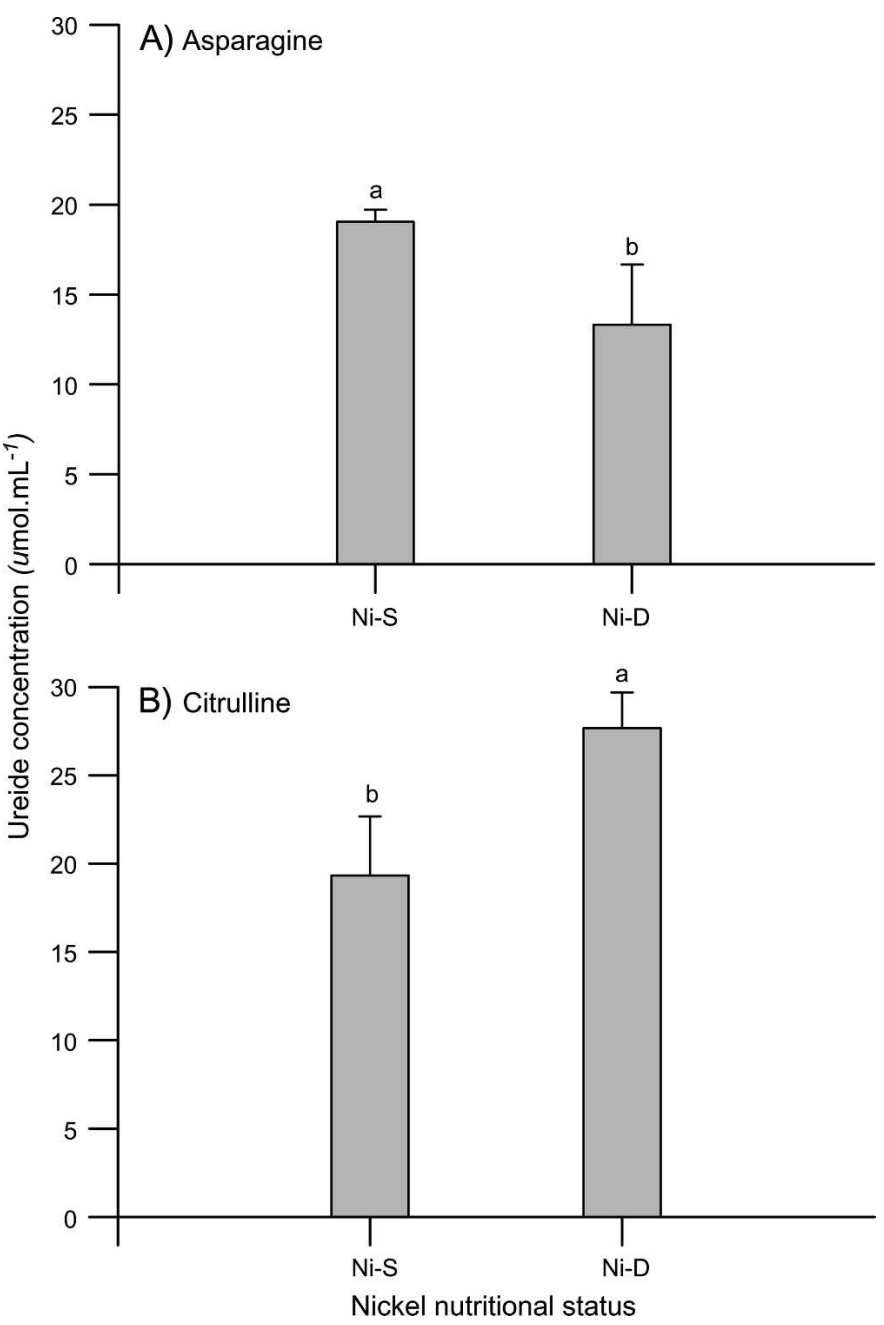

Fig. 2. Influence of pecan tree nickel nutritional status [Ni-deficient (Ni-D) and $\mathrm{Ni}$-sufficient $(\mathrm{Ni}-\mathrm{S})]$ on concentration of urea-cycle ureides and amides present in spring xylem sap at bud break. Asparagine (A) and citrulline (B) are the most abundant urea-cycle $\mathrm{N}$-forms found in the sap. Other urea-cycle $\mathrm{N}$-forms were present at trace levels $\left(\leq 0.50 \mu \mathrm{mol} \cdot \mathrm{mL}^{-1}\right)$. Different letters above the bar for each ureide designates statistical difference by ANOVA at $\alpha=0.05$.

characteristics). The catabolism of ureido-N compounds during xylem transport is additionally supported by the occurrence of several ureide catabolic pathway intermediates present in sap. Thus, spring xylem sap N-associated composition likely differs depending upon relative proximity to sinks (e.g., shoots) and sources (e.g., roots).

Nickel deficiency quantitatively alters xylem sap ureido-N composition in a manner similar to that observed in actively growing Ni-deficient pecan foliage (Bai et al., 2006), except that there was no detectable elevation of ureidoglycolate concentration in xylem sap of Ni-deficient trees, as was previously observed in foliage of Ni-deficient trees. This indicates that ureidoglycolate in xylem sap is being rapidly catabolized. The decline in sap of xanthine, and rise in allantoic acid, from Ni deficient trees, is evidence that Ni directly or indirectly affects ureide catabolism at one or more metabolic points, as was similarly found for ureide catabolism in actively growing spring foliage (Bai, et al., 2006). Thus deficiency potentially disrupts both the ureide catabolic pathway and the 


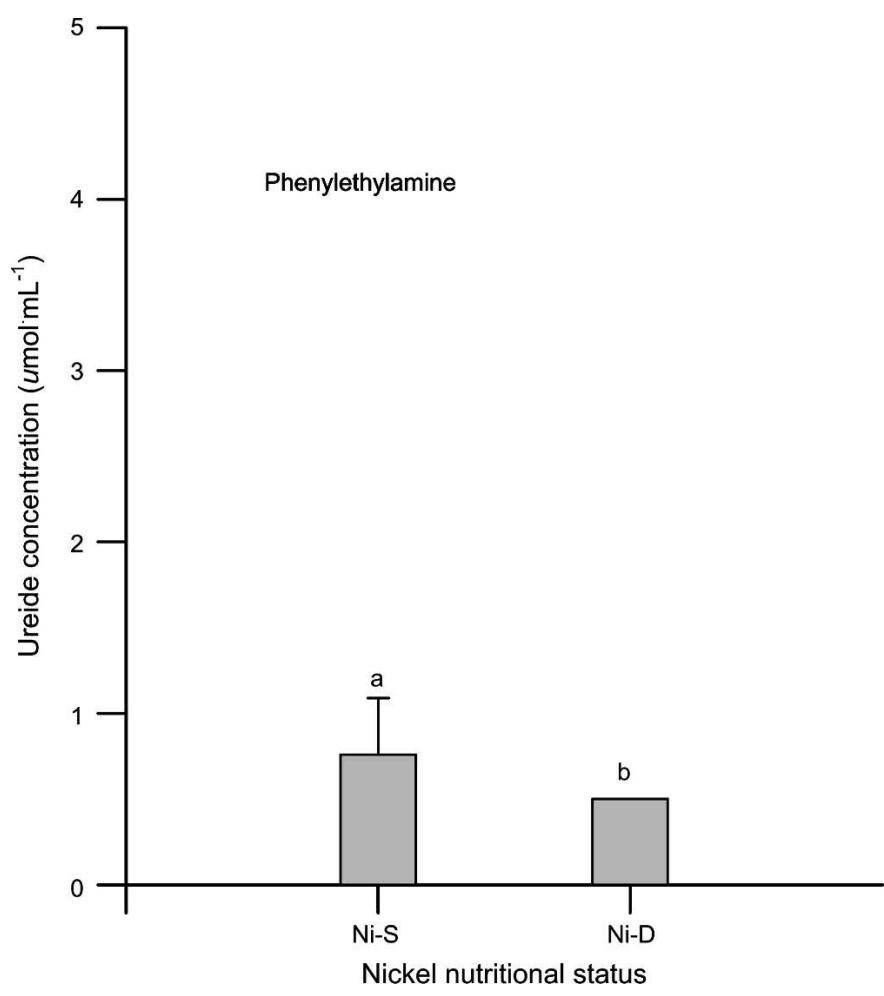

Fig. 3. Influence of pecan tree nickel nutritional status [Ni-deficient (Ni-D) and Ni-sufficient (Ni-S)] on $\beta$-phenylethylamine found in spring xylem sap at bud break. Different letters above the bar for each ureide designates statistical difference by ANOVA at $\alpha=0.05$.

Table 1 . Urease activity in purified $\geq 10-\mathrm{kDa}$ protein found in xylem sap of pecan trees at bud break as a function of nickel nutritional status. ${ }^{\mathrm{z}}$

\begin{tabular}{|c|c|c|}
\hline $\begin{array}{l}\text { Ni-deficiency } \\
\text { class }^{z}\end{array}$ & $\begin{array}{c}\text { Enzyme activity }^{\mathrm{y}} \\
{[\text { mean } \pm \mathrm{SD}} \\
\text { (units/mL crude enzyme) }]\end{array}$ & $\begin{array}{c}\text { Specific activity } \\
{[\text { mean } \pm \text { SD }} \\
\text { (units/mg protein) }]\end{array}$ \\
\hline$\overline{\mathrm{Ni}-\mathrm{D}}$ & $20.40 \pm 2.05 b^{x}$ & $10.20 \pm 1.03 b$ \\
\hline $\mathrm{Ni}-\mathrm{S}$ & $30.41 \pm 2.08 \mathrm{a}$ & $15.22 \pm 1.04 \mathrm{a}$ \\
\hline
\end{tabular}

${ }^{\mathrm{z}} \mathrm{Ni}-\mathrm{D}=\mathrm{Ni}$-deficient ( $\mathrm{Ni}$ in foliage at $0.004-0.54 \mu \mathrm{g} \cdot \mathrm{g}^{-1}$ dry weight), $\mathrm{Ni}-\mathrm{S}=\mathrm{Ni}$-sufficient ( $\mathrm{Ni}$ in foliage at $1-4 \mu \mathrm{g} \cdot \mathrm{g}^{-1}$ dry weight).

${ }^{\mathrm{y}} n=5$.

${ }^{\mathrm{x}}$ Means $( \pm \mathrm{SD})$ followed by the same letter are not significantly different $(P \leq 0.05)$ using ANOVA and the Student-Newman-Keul test.

Table 2. Nitrogen-to-carbon relationships of organic reduced-N substances in early spring xylem sap of pecan trees.

\begin{tabular}{lcr}
\hline Xylem sap component & Chemical formula & N/C ratio \\
\hline Allantoic acid & $\mathrm{C}_{4} \mathrm{H}_{8} \mathrm{~N}_{4} \mathrm{O}_{4}$ & $1: 1$ \\
Allantoin & $\mathrm{C}_{4} \mathrm{H}_{8} \mathrm{~N}_{4} \mathrm{O}_{3}$ & $1: 1$ \\
Uric acid & $\mathrm{C}_{5} \mathrm{H}_{4} \mathrm{~N}_{4} \mathrm{O}_{3}$ & $0.8: 1$ \\
Urea & $\mathrm{CH}_{4} \mathrm{~N}_{2} \mathrm{O}$ & $2: 1$ \\
Xanthine & $\mathrm{C}_{5} \mathrm{H}_{3} \mathrm{~N}_{4}$ & $0.8: 1$ \\
Ureidoglycolate & $\mathrm{C}_{3} \mathrm{H}_{6} \mathrm{~N}_{4} \mathrm{O}_{4}$ & $0.67: 1$ \\
Citrulline & $\mathrm{C}_{6} \mathrm{H}_{13} \mathrm{~N}_{3} \mathrm{O}_{3}$ & $0.5: 1$ \\
Asparagine & $\mathrm{C}_{4} \mathrm{H}_{8} \mathrm{~N}_{2} \mathrm{O}_{3}$ & $0.5: 1$ \\
Tryptamine & $\mathrm{C}_{10} \mathrm{H}_{3} \mathrm{~N}_{2}$ & $0.5: 1$ \\
3-Phenylethylamine & $\mathrm{C}_{8} \mathrm{H}_{11} \mathrm{~N}$ & $0.12: 1$ \\
\hline
\end{tabular}
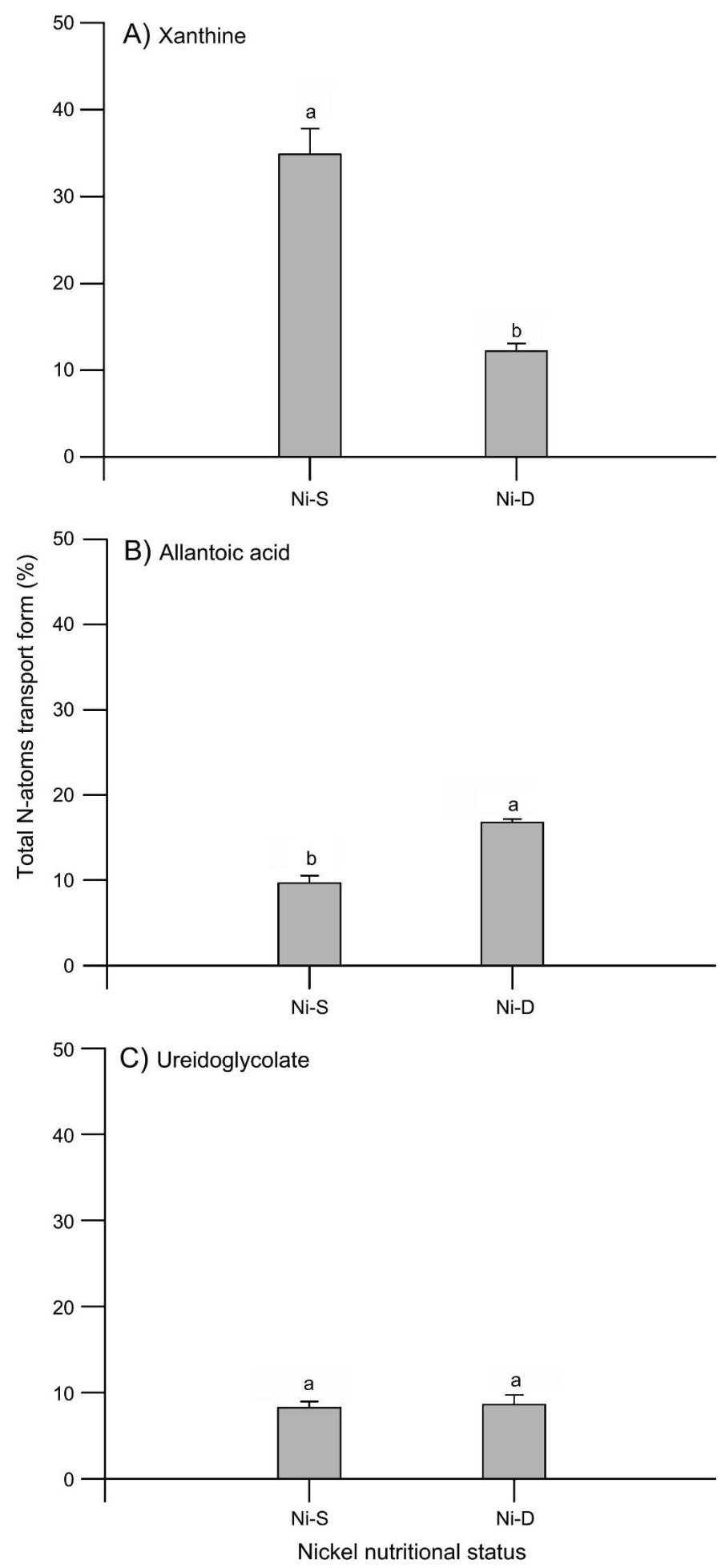

Fig. 4. Influence of pecan tree nickel nutritional status [Ni-deficient (Ni-D) and $\mathrm{Ni}$-sufficient (Ni-S)] on the relative abundance of ureido-N associated $\mathrm{N}$-atoms in spring xylem sap at bud break. Xanthine, allantoic acid, and ureidoglycolate are the most abundant ureides. Allantoin, uric acid, urea, and tryptamine are also present at trace levels $\left(\leq 0.50 \mu \mathrm{mol} \cdot \mathrm{mL}^{-1}\right)$. Different letters above the bar for each ureide designates statistical difference by ANOVA at $\alpha=0.05$.

urea-cycle metabolism (Figs. 7 and 8). The lower concentration of xanthine and higher concentration of allantoic acid in xylem sap of $\mathrm{Ni}-\mathrm{D}$ trees are both evidence that $\mathrm{Ni}$ is somehow affecting xanthine formation from purines or other sources 


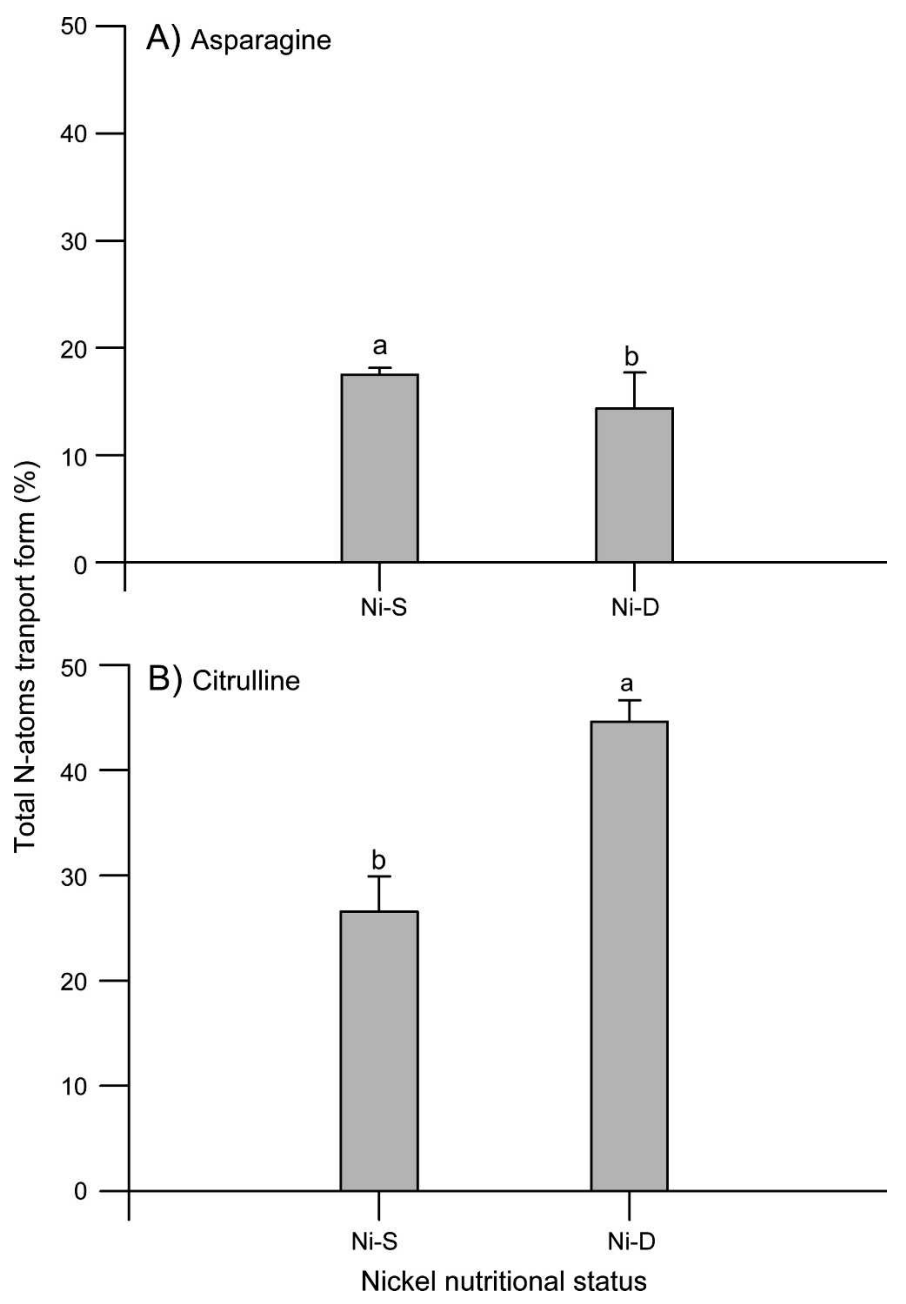

Fig. 5. Influence of pecan tree nickel nutritional status [Ni-deficient (Ni-D) and $\mathrm{Ni}$-sufficient $(\mathrm{Ni}-\mathrm{S})]$ on the relative abundance of urea-cycle associated $\mathrm{N}$-forms found in spring xylem sap of at bud break. Asparagine and citrulline are the most abundant urea-cycle $\mathrm{N}$-forms detected in sap. Other urea-cycle $\mathrm{N}$-forms were present at trace levels $\left(\leq 0.50 \mu \mathrm{mol} \cdot \mathrm{mL}^{-1}\right)$. Different letters above the bar for each ureide designates statistical difference by ANOVA at $\alpha=0.05$.

and also affects the enzymatic conversion of allantoic acid to ureidoglycine via allantoate amidohydrolase (Fig. 7). In the case of the urea cycle, Ni deficiency potentially increases citrulline and reduces asparagine concentrations in early spring xylem sap (Fig. 8). This metabolic shift indicates that Ni deficiency is directly or indirectly reducing the activity of either argininosuccinate synthase, which catalyzes citrulline to argininosuccinate, or asparagine synthase, which in turn catalyzes interconversion of L-asparate and L-asparagine.

Higher plants primarily transport organic $\mathrm{N}$ as amide-, amino-, or ureide- $\mathrm{N}$ forms, with ureide concentrations being relatively high in dormant roots of ureide- $\mathrm{N}$-transporting woody perennials (Schubert and Boland, 1990). These ureides are eventually exported with ascending spring xylem sap for assimilation into proteins and nucleic acids in newly growing tissues and organs (Schubert and Boland 1990). In the case of pecan, this organic reduced-N is predominately ureides. Pecan is therefore primarily a ureide- $\mathrm{N}$ transporter during early spring and is likely a predominate ureide- $\mathrm{N}$ transporter throughout the year. Because ureides contain more $\mathrm{N}$ atoms per molecule, and

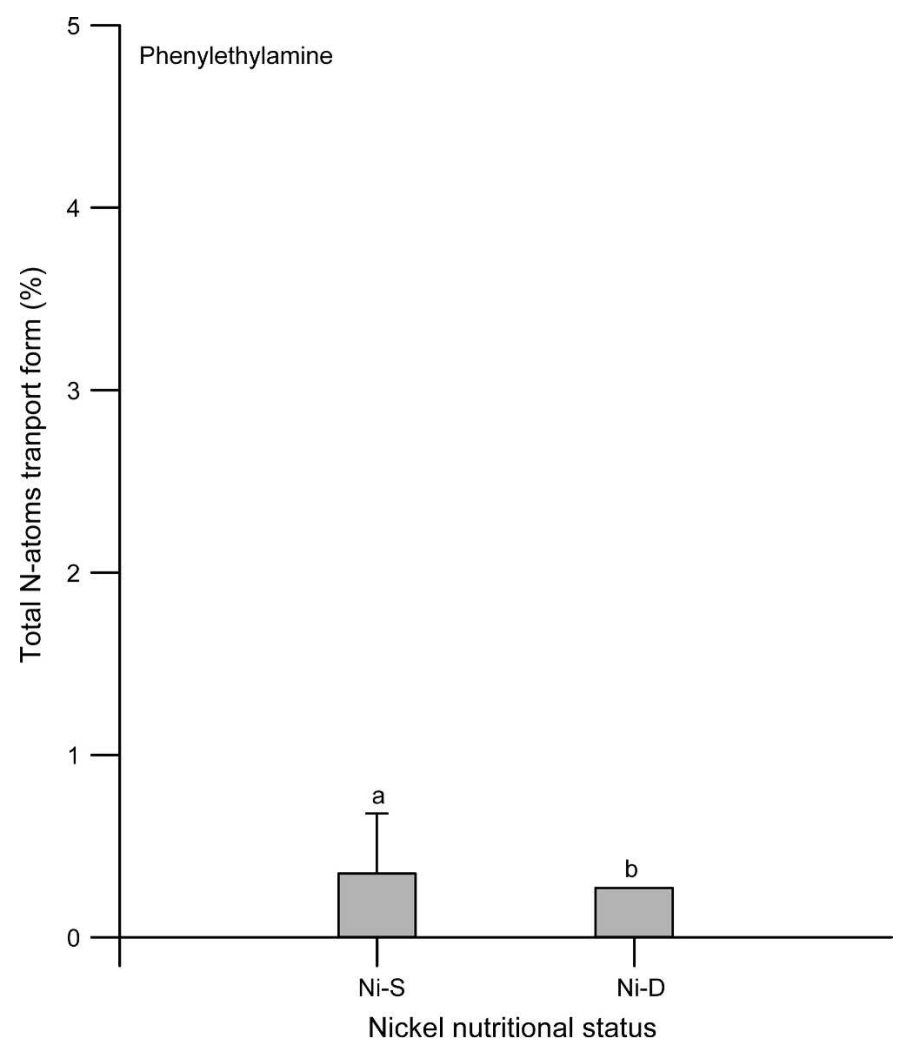

Fig. 6. Influence of pecan tree nickel nutritional status [Ni-deficient (Ni-D) and $\mathrm{Ni}$-sufficient $(\mathrm{Ni}-\mathrm{S})]$ on the relative abundance of $\mathrm{N}$-atoms present as $\beta$-phenylethylamine in spring xylem sap at bud break. Different letters above the bar for each ureide designates statistical difference by ANOVA at $\alpha=0.05$.

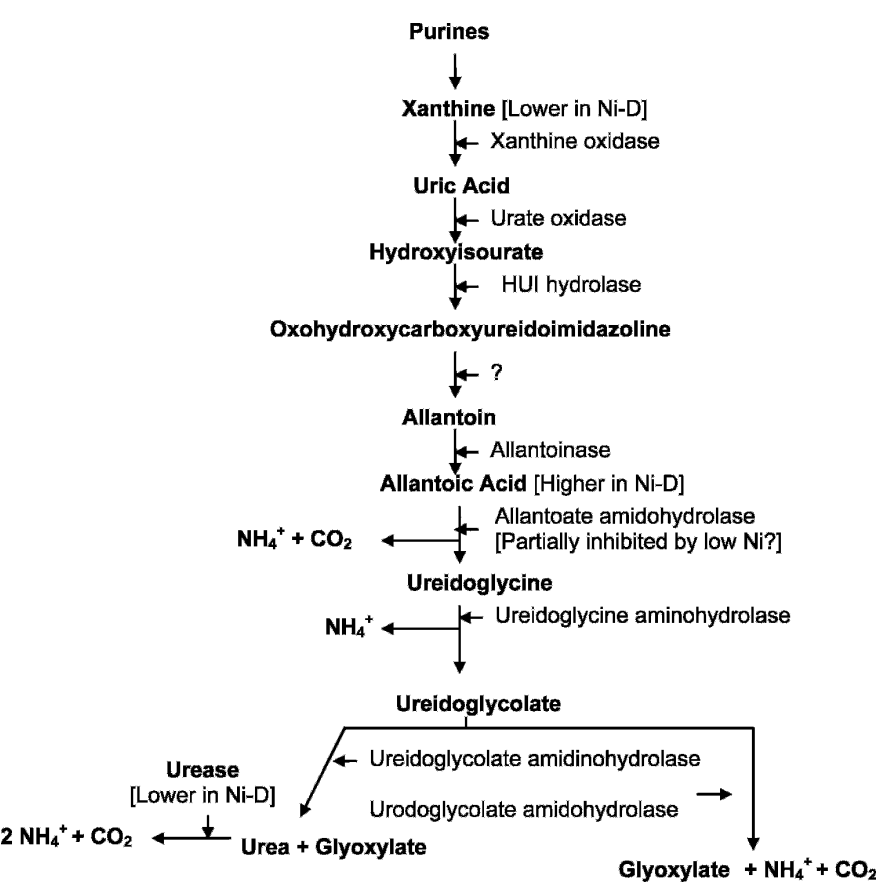

Fig. 7. Influence of tree nickel nutritional status on ureide catabolic intermediates found in early spring xylem sap of either $\mathrm{Ni}$ deficient (Ni-D) or Ni sufficient (Ni-S) pecan trees. Pathway is from Schubert and Boland (1990) but modified according to Todd et al. (2006). 


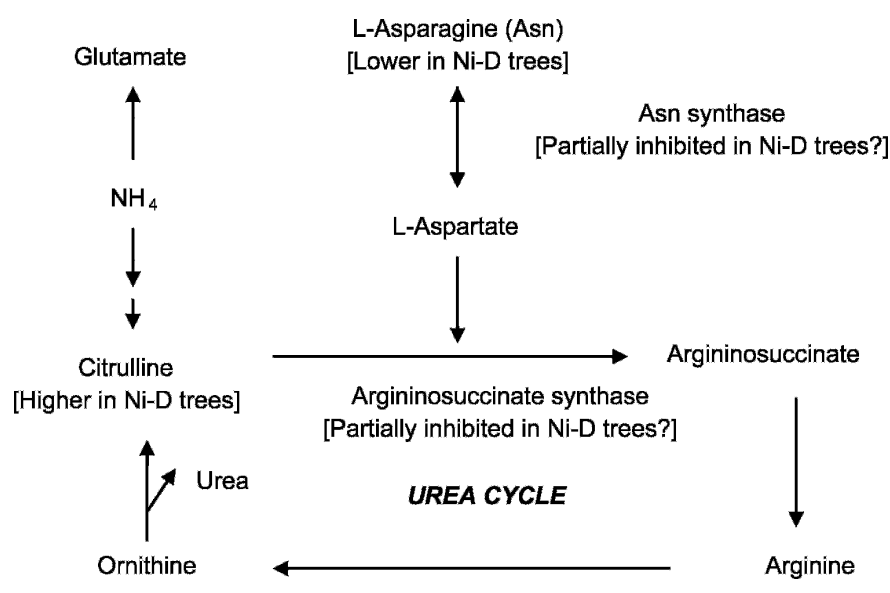

Fig. 8. Changes in urea-cycle intermediates (Nicholson, 2003) found in pecan xylem sap at bud break as a consequence of differences in tree nickel nutritional status [Ni-deficient (Ni-D) and Ni-sufficient (Ni-S)].

have a higher $\mathrm{N} / \mathrm{C}$, than do standard amide- or amino- $\mathrm{N}$ forms (e.g., allantoic acid, allantoin, uric acid, and xanthine contain four $\mathrm{N}$-atoms; urea and ureidoglycolate contain two N-atoms; citrulline contains three $\mathrm{N}$-atoms; asparagine and tryptamine contain two N-atoms; and $\beta$-phenylethylamine contains one $\mathrm{N}$-atom), the reduced-N transported by pecan in early spring is primarily in forms favoring a high $\mathrm{N} / \mathrm{C}$ ratio. Thus, pecan transports $\mathrm{N}$ using fewer $\mathrm{C}$-atoms per transported $\mathrm{N}$-atom than do non-ureide-N-transporting species and, in an energetic sense, is a high-efficiency $\mathrm{N}$-transporter, apparently requiring less energy for $\mathrm{N}$ transport (Mothes, 1961; and Polayes and Schubert, 1984). Many hydrophilic woody perennials exhibit this ureide-transporting characteristic; hence, invoking questions as to the nature of selection pressures acting to favor this level of N/C economy in pecan. It is postulated that ureido-Ntransporting species possess a competitive advantage in habitats where energy (i.e., C) is especially limiting and water is relatively nonlimiting (Schubert and Boland, 1990). This is consistent with the potentially low light and moist soil habitat to which pecan is native and to similar ecological niches in which the other ureido-N-transporting hydrophilic species are native. The relatively low water solubility of most ureides $(\approx 0.07-5.7$ $\left.\mathrm{g} \cdot \mathrm{L}^{-1}\right)$, relative to amides or amines $\left(\approx 29-250 \mathrm{~g} \cdot \mathrm{L}^{-1}\right)$ (Schubert and Boland, 1990), could explain why the ureido-N-transporting pecan grows and fruits best in moist ecological niches (or well-irrigated orchards), where the relatively high water requirement of pecan enables transport of reduced-N in relatively low soluble ureido- $\mathrm{N}$ forms. This characteristic is consistent with the observation that pecan trees and orchards perform best when supporting soils are moist during key phases of $\mathrm{N}$ mobilization associated with canopy deployment and canopy senescence.

The influence of Ni deficiency, or tree Ni nutrition status, on the relative composition of xylem sap ureides obviously affects tree $\mathrm{N} / \mathrm{C}$ economy and associated energetics. The observed Niassociated shift in spring xylem sap ureido-N from ureides with a relatively high N/C ratio (e.g., xanthine and others; $\mathrm{N} / \mathrm{C}=1: 1$ to $2: 1$ ) to those with a relatively low N/C ratio (e.g., citrulline; $\mathrm{N} / \mathrm{C}=0.5: 1)$ means that tree $\mathrm{Ni}$ status not only potentially affects the forms of organic-N reaching sinks but also disrupts associated N/C economy and energetics. Thus Ni-deficient pecan trees require more $\mathrm{C}$-atoms for the transport of $\mathrm{N}$ than do Ni-sufficient trees.

It is concluded that tree $\mathrm{Ni}$ deficiency quantitatively affects ureide and amide metabolism; alters the concentration and relative composition of xanthine, allantoic acid, asparagine, citrulline, and $\beta$-phenylethylamine in spring xylem sap; alters the tree's N/C economy; reduces sap-associated urease activity; and disrupts ureide and urea-cycle metabolism. The adverse effect of $\mathrm{Ni}$ deficiency on $\mathrm{N}$ metabolism is evidence that the efficacy of N-management of ureido-N-transporting species is potentially influenced by crop Ni nutritional status. It is also concluded that pecan is not only predominantly a ureido-Ntransporting species but also that ureido-N forms are catabolized in spring sap while organic-N is transported to sinks. These findings present evidence that $\mathrm{Ni}$ nutritional status potentially impacts $\mathrm{N}$-associated processes of ureido-N-transporting species.

\section{Literature Cited}

Bai, C., E. Fernandez, H. Yang, and R. Chen. 1999. Purification and stabilization of a monomeric isocitrate dehydrogenase from Corynebacterium glutamicum. Protein Express Purification 15: 344-348.

Bai, C., C.C. Reilly, and B.W. Wood. 2006. Nickel deficiency disrupts metabolism of ureides, amino acids, and organic acids of young pecan foliage. Plant Physiol. 140:433-443.

Bloom, A.J. 2002. Mineral nutrition, p. 67-86. In: L. Taiz and E. Zeiger (eds). Plant physiology. Sinauer Associates, Sunderland, Mass.

Brown, P.H., R.M. Welch, and E.E. Cary. 1987a. Nickel: a micronutrient essential for higher plants. Plant Physiol. 85:801-803.

Brown, P.H., R.M. Welch, E.E. Cary, and R.T. Checkai. 1987 b. Beneficial effects of nickel on plant growth. J. Plant Nutr. 10:21252135.

Brown, P.H., R.M. Welch, and J.T. Madison. 1990. Effect of nickel deficiency on soluble anion, amino acid, and nitrogen levels in barley. Plant Soil 125:19-27.

Dixon, N.C., C. Gazzola, R.L. Blakely, and R. Zemer. 1975. Jack bean urease (EC 3.5.1.5). A metalloenzyme. A simple biological role for nickel. J. Amer. Chem. Soc. 97:4131-4133.

Dobrolyubskii, O.K. and A.V. Slavvo. 1957. Use of trace element nickel for the nutrition of grapes. Dokl. Akad. Nauk SSSR 112: 347-359.

Eskew, D.L., R.M. Welch, and E.E. Cary. 1983. Nickel and essential micronutrient for legumes and possibly all higher plants. Science 222:691-693.

Eskew, D.L., R.M. Welch, and W.A. Norvell. 1984. Nickel in higher plants: further evidence for an essential role. Plant Physiol. 76: 691-693.

Gerendás, J. and B. Sattelmacher. 1997. Significance of Ni supply for growth, urease activity and concentrations of urea, amino acids and mineral nutrients of urea-grown plants. Plant Soil 190:153-162.

Kaltwasser, H. and H.G. Schlegel. 1966. NADH-dependent coupled enzyme assay for urease and other ammonia-producing systems. Anal. Biochem. 16:132-138.

Mothes, K. 1961. The metabolism of urea and ureides. Can. J. Bot. 39:1785-1807.

Nicholson, D.E. 2003. Metabolic pathways. 15 Oct. 2006. <http:// www.sigmaaldrich.com/img/assets/4202/MetabolicPathways_updated_ 4.19.05.pdf $>$.

Nyczepir, A.P., B.W. Wood, and C.C. Reilly. 2006. Association of Meloidogyne partityla with nickel deficiency of mouse-ear of pecan. HortScience 41:402-404.

Ourry, A., J.H. McDuff, J.J. Volened, and J.P. Gaudillere. 2001. Nitrogen traffic during plant growth and development, p. 255-274. 
In: P.J. Lea and J.F. Morot-Gaudry (eds.). Plant nitrogen. Springer, New York.

Polayes, D.A. and K.R. Schubert. 1984. Purine synthesis and catabolism in soybean seedlings. Plant Physiol. 75:1104-1110.

Roach, W.A. and C. Barclay. 1946. Nickel and multiple trace-element deficiencies in agricultural crops. Nature 157:696.

Ruter, J.M. 2005. Effect of nickel applications for the control of mouse ear disorder on river birch. J. Environ. Hort. 23:17-20.

Reilly, C.C., M. Crawford, and J.W. Buck. 2005. Nickel suppresses daylily rust, Puccinia hemerocallidis on susceptible daylilies, Hemerocallis ssp. in greenhouse and field trials. Phytopathology 95:588 (abstr.).

Schubert, K.R. and M.J. Boland. 1990. The ureides, p. 197-283. In: B.J. Miflin and P.J. Lea (eds.). The biochemistry of plants, Vol. 16. Academic Press, San Diego.

Sirko, A. and R. Brodzik. 2000. Plant ureases: roles and regulation. Acta Biochim. Pol. 47(4):1189-1195.
Todd, C.C., P.A. Tipton, D.G. Blevins, P. Piedras, M. Pineda, and J.C. Polacco. 2006. Update on ureide degradation in legumes. J. Expt. Bot. 57:5-12.

Walker, D.W., R.D. Graham, J.T. Madison, E.E. Cary, and R.M. Welch. 1985. Effects of Ni deficiency on some nitrogen metabolites in cowpeas (Vigna unguiculata L. Walp). Plant Physiol. 79: 474-479.

Welch, R.M. 1981. The biological significance of nickel. J. Plant Nutr. 3:345-356.

Wood, B.W., C.C. Reilly, and A.P. Nyczepir. 2004a. Mouse-ear of pecan: I. Symptomology and occurrence. HortScience 38:87-94.

Wood, B.W., C.C. Reilly, and A.P. Nyczepir. 2004b. Mouse-ear of pecan: II. Influence of nutrient applications. HortScience 38:95-100.

Wood, B.W., C.C. Reilly, and A.P. Nyczepir. 2004c. Mouse-ear of pecan: a nickel deficiency. HortScience 39:1238-1242.

Wood, B.W., C.C. Reilly, and A.P. Nyczepir. 2006. Field deficiency of nickel in trees: symptoms and causes. Acta Hort. 721:83-98. 